\title{
SYNCHRONOUS PATENT FORAMEN OVALE AND BRONCHOPLEURAL FISTULA AFTER RIGHT PNEUMONECTOMY: NONOPERATIVE MANAGEMENT WITH SURVIVAL
}

\author{
K. Adam Lee, MD, and A. Alan Conlan, MD, Worcester, Mass.
}

The occurrence of an acute right-to-left shunt after pneumonectomy has been reported in only 20 cases. Bronchopleural fistula (BPF) and postpneumonectomy empyema are common in $2 \%$ to $5 \%$ of patients, with mortality ranging between $20 \%$ and $70 \%$. Synchronous patent foramen ovale (PFO) and BPF has not been reported in the literature. The successful nonoperative control of these two major postpneumonectomy complications is described.

A 70-year-old man underwent a right pneumonectomy for stage II adenocarcinonoma. Preoperative lung function studies and preoperative blood gas are presented in Table I.

The immediate postpneumonectomy course was complicated by profound hypoxemia noted on the evening of the operation when the patient was recumbent. The mediastinum was sharply shifted into the postpneumonectomy space (Fig. 1). The postpneumonectomy drainage tube was unclamped and air injected to centralize the mediastinum. This dramatically relieved the hypoxemia, improving oxygen saturation from $77 \%$ to $98 \%$ with the patient breathing $100 \%$ oxygen delivered by means of a face mask. The patient had periods of hypoxia in both the recumbent position (platypnea) and the upright position (orthodeoxia), necessitating daily centralization of the mediastinum.

An echocardiogram revealed an acute intraatrial shunt. Almost synchronously with the diagnosis of the shunt, the patient had a paradoxic embolism to the left suboccipital region that resulted in a right hemianopia.

Symptoms of cough, hemoptysis, and fever developed on postoperative day 14 , and a clinical diagnosis of BPF was made. The space on the right side was drained with a chest tube. The BPF was closed temporarily by endoscopic

From the Cardiothoracic Surgery Department, University of Massachusetts, Worcester, Mass.

Received for publication Oct. 3, 1997; accepted for publication Oct. 17, 1997.

Address for reprints: K. Adam Lee, MD, Cardiothoracic Surgery, University of Massachusetts, Worcester, MA 01655-0304.

J Thorac Cardiovasc Surg 1998;115:951-2

Copyright (c) 1998 by Mosby, Inc.

$0022-5223 / 98 \$ 5.00+0 \quad \mathbf{1 2 / 5 4 / 8 7 0 4 6}$ placement of a felt pledget into the defect, and it was oversealed with fibrin glue. This resulted in closure of the BPF with no further air leakage.

Several days later, the interatrial defect was effectively closed by transvenous placement of a $33 \mathrm{~mm}$ double clamshell device (Nitinol; Boston, Mass.). Symptoms lessened immediately, and oxygen saturation returned to $95 \%$. Supplemental oxygen was discontinued and the closed drainage system of the empyema was converted to open drainage by a thoracostoma. Subsequent follow-up examinations at $1,3,6$, and 8 months show that the BPF has closed spontaneously.

Discussion. The common causes of dyspnea after pneumonectomy are chronic obstructive pulmonary disease, loss of alveolar volume, pain, restriction of the vascular bed, and diaphragmatic dysfunction. ${ }^{1}$ Acute PFO is uncommon and numerous mechanisms for its appearance have been postulated. The weight of the heart after a right pneumonectomy causes a shift that pulls the interatrial septum downward, causing the foramen ovale to open or widen. $^{2}$ PFO is found in approximately $20 \%$ of postmortem studies in the general public. The heart in this new position provides a direct course for blood from the inferior vena cava through the PFO (streaming effect). Distortion is accentuated in an upright position, creating an increasing shift of the right atrium and widening the orifice of the $\mathrm{PFO}^{3}$ A pressure gradient is created across the PFO, producing a large shunt and the symptoms of orthodeoxia and platypnea. Another theory is based on the anatomic distortion and decreased compliance of the

Table I. Preoperative pulmonary function test

\begin{tabular}{|c|c|c|c|}
\hline & Actual & Predicted & $\%$ \\
\hline FVC (L) & 4.42 & 4.37 & 101 \\
\hline $\mathrm{FEV}_{1}(\mathrm{~L})$ & 3.22 & 2.94 & 110 \\
\hline $\mathrm{FEF}_{25 \%-75 \%}(\mathrm{~L} / \mathrm{sec})$ & 2.14 & 2.65 & 81 \\
\hline $\mathrm{FEV}_{1} / \mathrm{FVC}(\%)$ & 73 & 67 & 108 \\
\hline $\operatorname{MVV}(\mathrm{L} / \mathrm{min})$ & 132 & 117 & 112 \\
\hline $\begin{array}{l}\text { Arterial blood gas } \\
\text { values }\end{array}$ & $7.42 / 32 / 88 / 20 / 96 \%$ & & \\
\hline
\end{tabular}

$F E F$, forced expiratory flow; $M V V$, maximal voluntary ventilation. 


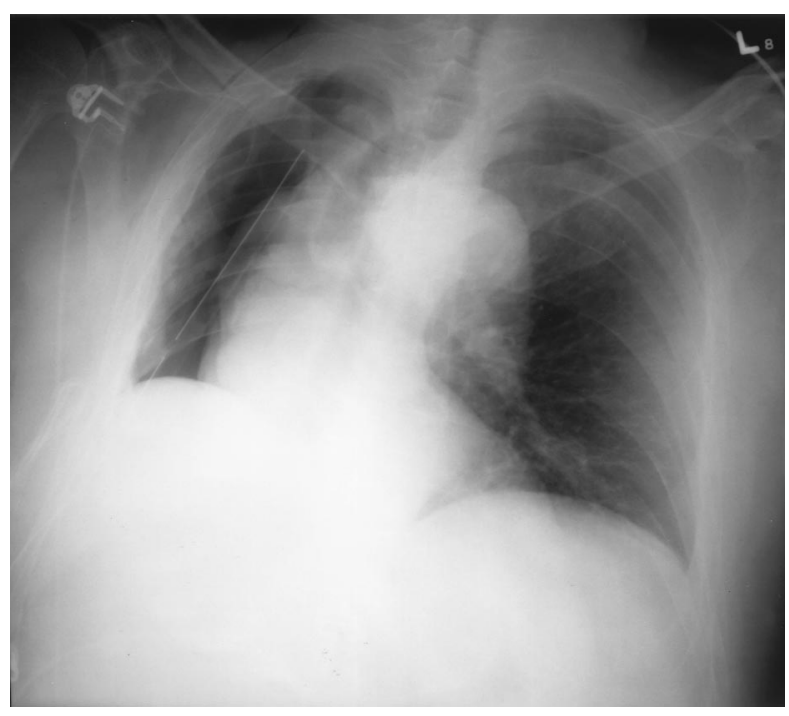

Fig. 1. Chest radiograph showing shifting of the mediastinum into the postpneumonectomy space.

right ventricle, which may result in a right-to-left interatrial shunt.

Closure of the PFO is indicated to relieve the symptoms of orthodeoxia and platypnea. Treatment options range from open cardiac operations (most common) to conservative methods like transcatheter closure. Cardiac surgery presents another major surgical procedure and is contraindicated in the presence of a BPF and empyema. Transcatheter closure provides a minimal invasive technique to close the PFO.
BPF after pneumonectomy is one of the most formidable complications in thoracic surgery. The overall incidence of postresectional BPF is $1 \%$ to $5 \%$. Endoscopic closure with pledget and glue application improved clinical health. Endoscopic closure has been shown to be successful in $50 \%$ of patients with $\mathrm{BPFs}^{4}$ and has been promoted as a first line of therapy. ${ }^{5}$ Bronchial stump sealing provided stability for placement of the clamshell device. Later, definitive drainage of the empyema was performed by means of an Eloesser flap.

Conclusion. Synchronous PFO and BPF presents extreme challenges after postpneumonectomy. A minimal invasive approach with endoscopic control of the BPF and transvenous closure of the PFO avoided major surgical procedures in a patient who was in greatly compromised condition. Permanent closure of the BPF has occurred after thoracostoma drainage.

\section{REFERENCES}

1. Mercho N, Stoller JK, White RD, Mehta AC. Right to left interatrial shunt causing platypnea after pneumonectomy. Chest 1994;105:931-3.

2. Swan HJ, Burchell HB, Wood EI. The presence of venoatrial shunts in patients with intracardiac communication. Circulation 1954;10:705-13.

3. Berry L, Braude S, Hagan J. Refractory hypoxemia after pneumonectomy: diagnosis by transesophageal echocardiograph. Thorax 1992;47:60-1.

4. Torre M, Quaini E, Ravini M, Nerli FP, Maioli M. Endoscopic gluing of bronchopleural fistulae. Ann Thorac Surg 1994;58:901-2.

5. York EG, Lewall DB, Hirji M, Gelfand ET, Modry DL. Endoscopic diagnosis and treatment of postoperative bronchopleural fistula. Chest 1990;97:1390-2. 